\title{
Method of EFL Instruction and its Dependence on Learners Reading Comprehension
}

Mehrnoosh Eslami*, Mahmoud Shaker, Fatemeh Rakhshandehroo

University of Applied Science and Technology, Shiraz, Iran

Corresponding Author: Mehrnoosh Eslami, E-mail: nedarakhsh62@gmail.com

\begin{tabular}{l} 
ARTICLE INFO \\
\hline Article history \\
Received: November 26, 2017 \\
Accepted: January 04, 2018 \\
Published: March 01, 2018 \\
Volume: 7 Issue: 2 \\
Advance access: February 2018
\end{tabular}

Conflicts of interest: None

Funding: None

\begin{abstract}
Today's research suggests that stress can block chemical reactions in the brain that are necessary for learning. To illuminate how it can be destructive for EFL learners in reading comprehension, the present study used two classes one in which the subjects were asked to paraphrase a reading comprehension text before it was taught by the teacher (class1) and another in which the teacher taught the reading passage first and then asked the students some questions about it (class2). The data were gathered through 2 instruments, namely, a test and indirect observation. The analysis of the results indicated that students in the class in which the teachers had taught the lesson first and had then asked questions performed better and had less signs of stress in comparison with the other group. Overall, the results indicate that in class 1 since the subjects are under the pressure and stress of being singled out, they constantly read the next paragraph without paying attention to the paragraph which was being presented by their classmate and the teacher. However, the case is vice versa in class 2 since as the teacher teaches the passage, students pay attention to her carefully in order to answer her questions after reading the passage without any stress on being called upon to read in a passage which they are not familiar with yet.
\end{abstract}

Key words: Learner Reading Comprehension, Method of Reading Instruction, Reading Comprehension Passages, EFL Learner

\section{INTRODUCTION}

Stress affects everyone and it has been defined as 'any characteristic of the job environment which poses a threat to the individual -either excessive demands or insufficient supplies to meet his needs' (French et al. 1976). To raise creativity and learning we have to introduce new ways or instructional strategies to reduce levels of the stress in classrooms. According to Lazarus (1966), stressful events can be appraised by an individual as "challenging" or "threatening". Thus, it is important to find out whether what conditions may lead to these situations in order to prevent them.

\section{REVIEW OF LITERATURE}

The literature review summarized the research done on the difficulty of reading comprehension and how it can be a stressful task for EFL learners and the means by which instruction can be utilized to decrease it. It is believed that Junior and high school EFL students experienced problems when taking reading comprehension text. Reading in a foreign language causes anxiety and can lead to poor language achievement "in conjunction of students' levels of reading anxiety and general foreign language anxiety" (Saito, Thomas, \&Horwitz, 1999, p. 202). Unfamiliar scripts, writing systems, and unfamiliar cultural material cause EFL reading anxiety (p. 215). Zhang (2000) believes that "Low language proficiency and teacher diversity may be causing an emotional block" (p. 31) in ESL/EFL students when they have anxiety in completing a reading comprehension text.

Sometimes many other variables cause stress. Many ESL learners also have reading disabilities. As Karen Woodman (2001), a linguistics professor at the University of New England in Australia mentioned the challenge in which teachers need to pay attention to "is deciding when a student's problem relates to learning English, and when it is a disability" (SER, 2001, p. 2). Limbos \&Geva, (2001) have conducted a study on accuracy of teacher assessments of second language students at risk for reading disability. The study sets out to "examine the accuracy of various teacher assessment methods for screening children for reading disability" (p.136). Feelings of discomfort and anxiety in the classroom do not enhance learning of any kind. Sanz (1999) has written a research paper on the relationship between reading, anxiety, and reading comprehension in foreign language learners. Unfortunately, very little research has been conducted to date on the role of anxiety in English reading comprehension. She conducted her research studies on Spanish and not on ESL. In another reading comprehension research done on Japanese ESL students, Sanz tried to find the relationship between foreign language classroom anxiety scales and foreign language reading anxiety scales based on an in- 
structional method in which the results indicated that these two parameters are not related and they measure completely different components (Saito et al., 1999).

It would be interesting to repeat the research in another setting where English is the foreign language and Farsi is the first language with different methods of instruction which are used in Iran. Foreign language anxiety only increases students' problems with "decoding of a text and the actual processing of textual meaning” (Saito et al., 1999. p.215). Moreover, the research implications show that there may be differences between beginners and advanced EFL students. As Saito et al stated, "In the case of beginning students confronted with unfamiliar phonology and scripts, the anxiety might be more immediate" (p.215). This is the case in the present study which it deals with intermediate students to indicate how special instruction can be effective in reducing anxiety and stress exist in reading comprehension texts. As will be shown, in this study the instruction based on which the subjects were asked to paraphrase a reading comprehension text before it was taught by the teacher was stressful for them and decreased their learning while the method in which the teacher taught the reading passage first and then asked the learners some questions increased their learning.

Therefore, the research question based on which the present research is conducted is to see any relationship between the method of EFL instruction and EFL learner's reading comprehension.

\section{METHOD}

\section{Participants}

This study included sixty five students, only female, aged between 15 to 20 who were divided into two groups of thirty two and thirty three with the same characteristics at intermediate level of General English in Shiraz, Iran. As the students were chosen from a single institute they were homogenous based on the fact that they had passed a placement test before being placed into their class. Hence, their level of English proficiency was the same. The reason for selecting these students at this level was that they had passed the introductory courses in learning English and had developed the necessary skills for second language reading comprehension and speaking understandably. Therefore, the element of stress that commonly exists among students with low ability of communicating in a second language was controlled. Additionally, they had all been students of the same institute for several semesters prior to the conduct of this research. Based on institute rules, classed were conducted in a manner based on which learners were familiarized with the four skills and were also provided with opportunities to communicate in the second language and improve their reading, writing, speaking and listening skills.

\section{Instruments}

Two instruments were utilized in the process of collecting data for the present study. To gain information on the participant's in-depth thoughts and experiences, the first instrument was chosen as indirect observation in order to collect the data as naturally as possible. Given that the objective of this study is to evaluate the effect of stress on decreasing language learning among EFL students, the learners were not informed that they were being a part of a scientific study so this fact would not interfere with how they conduct themselves throughout the administration of the research. In addition, the two classes chosen for the purposes of the study were administered by the same teacher teaching the same book in order to control any extra variables and mainly focus on the element of stress. In order to adhere the accuracy of the hypothesis, a paper and pencil test was given to subjects after the teacher had completely taught them the reading text. The quantitative data obtained from this test help make the result more representative of the population under study. As the book taught was from Cambridge publication and the test was from the publication and the authors, the reliability of the written test is confirmed. Three special questions were constructed for each passage. These questions were asked regarding: (1) Grammatical rule, (2) lexical words, and (3) reading comprehension questions. The allowed time to answer all three categories was 30 minutes for both groups and each participant.

\section{DESIGN}

This study was a descriptive research in which the researcher's interference was not seen throughout the administration of the study. The role of the researcher in this study was to merely report the relationship between the method of instruction and EFL learning. In order to control many factors in the study, control variable were used such as age (15 to $20)$, gender (restraint to female only), material (Same book) and the teacher (the same in the two groups).

\section{Procedure}

Necessary data for this study was collected in two phases. First of all, two classes were chosen with seventeen subjects in each. In 21 sections and 10 reading comprehension passages the data were gathered. In class 1 , the students were randomly chosen and asked to read and paraphrase a paragraph and then asked some lexical, grammatical, cultural and general questions. This procedure was carried out throughout the instruction of the entire reading text. On the other hand, in class 2, the teacher first taught the lesson completely and then discusses its lexical, grammatical, cultural characteristics in a communicative way. The questions were asked after the reading and presentation of the text has come to an end. After that, a paper and pencil test which consisted of 20 items was distributed between all of the subjects. The test consisted of twenty questions on grammar, reading comprehension and lexical understanding, with one point for each question. The subjects were not only expected to answer each question but to also explain their answers. The questions were scored to identify the differences between the groups. During the second phase of the study which lasted for about three months, the observation data were collected. In fact, the teacher as one of the cooperators of this study 
reported students' behavior in each of the class by recording the class procedure.

\section{Data Analysis}

To answer the research question, a number of descriptive and inferential statistics were run on the data for comparative purposes. To identify the differences, a samples t-test was run. For the observation, the selected classes were audio-taped. The coding for each observed class was carried out independently. To determine the manner in which stress caused by the method of instruction can be a barrier for EFL learner's reading comprehension the tests were carefully scored. The obtained data was coded based on an interval scale in order to make its interpretation using inferential statistics easier. The first step in interpreting the results was to compute the mean of each class independently from each other; the second step was to take a t-test to understand the differences between the two obtained means.

\section{RESULTS}

Table 1 depicts the results obtained from the descriptive statistics concerning the performance of the two groups on reading comprehension test. As illustrated, the mean scores of both groups are compared and class 2 has the higher mean scores in the reading comprehension test. This is indicative of the idea that the participants in class 2 perform better than students in class 1 .

In order to see whether the differences depicted in Table 1 were statistically significant or not, a sample t-test was utilized. The obtained results, depicted in Table 2, indicated that class 2 performed better on the test as the differences were significant at $\mathrm{p}<0.01$. The eta scored statistic also indicated a large effect size for all the depicted differences based on Cohen (1988).

Furthermore, the results obtained from classroom observations based on a total of $42 \mathrm{hr}$ of observation for each class indicated that forcing the EFL learner to discuss about the lesson which has not yet been taught causes a stress barrier for their understanding of the reading comprehension passage and hence can be concluded that there is a relationship between method of instruction and EFL learner's reading comprehension. In another word, in class 1 since the subjects are under the pressure and stress of being singled out, they constantly read the next paragraph without paying attention to the paragraph which was being presented by their classmate and the teacher. However, the case is vice versa in class 2 since as the teacher teaches the passage, students pay attention to her carefully in order to answer her questions after reading the passage without any stress on being called upon to read in a passage which they are not familiar with yet.

\section{DISCUSSION}

The results of this study provide support for the efficacy of class 2 over class 1 . Using $t$ test and observations, the results indicated that students in class 2 consistently outperformed those in class 1 in the area of reading comprehension. When a t tests was conducted to explore possible performance disparities between the two groups, it was found that there were significant differences between the two groups. The effect sizes indicated that the differences in all the cases were large enough to be considered important. These findings are similar to the ones obtained by Sanz (1999) who conducted research in this regard but focused on Japanese and Hebrew; however, the present research focused on learners' whose first language was Farsi. Several reasons could be mentioned for the efficiency of class 2 according to the results of the observations and t test. First of all, in line with Frey (1980), reducing stress can significantly improve the performance of learning reading, arithmetics, and spelling and handwriting (Hughes, Jackson, Dubois, and Erwin, 1979) among disabled teenagers. Moreover, the findings lend support to the idea of stress and its negative effects on the overall success and achievements of students here reading comprehension in line with many studies in this regard. (Saito, Thomas, \&Horwitz, 1999; Zhang, 2000, Karen Woodman, 2001; Limbos \&Geva, 2001).

To point out the limitations of the present study, the main limitation includes the fact that the population under investigation did not include male learners in order to assess the impact of gender on the amount of stress experienced by the participants. Another limitation was the fact that the researcher solely assessed the class of one teacher from a single institute which makes the generalization of the results challenging and forced the researcher to choose

Table 1. Descriptive statistics for the performance on the reading comprehension test

\begin{tabular}{lccccc}
\hline Group statistics & & & & & \\
\hline & Group & N & Mean & Standard deviation & Standard error mean \\
\hline $\begin{array}{l}\text { Reading } \\
\text { comprehension }\end{array}$ & Class 1 & 33 & 48.7900 & 6.38068 & 0.63807 \\
& Class 2 & 32 & 67.6111 & 7.72955 & 0.81477 \\
\hline
\end{tabular}

Table 2. Independent sample T-test for the group differences

\begin{tabular}{lccccc}
\hline & \multicolumn{4}{c}{ t-test for equality of means } \\
\cline { 2 - 6 } & $\mathbf{t}$ & df & Sig. (2-tailed) & Mean difference & Standard error diference \\
\hline Reading comprehension & 18.37 & 188 & 0.000 & 18.82111 & 1.02456 \\
\hline
\end{tabular}


purposive sampling in non-random sampling with a short number of students and classes rather than random sampling which is more valid. Therefore, further research can be conducted in order to remove such limitations and confirm the results obtained from the present study. This research can be used by EFL teachers, institutes, and school and colleges in order to help design EFL reading comprehension courses in a manner which can reduce the stress of the learners and lead to more productivity in this specific language skill.

\section{CONCLUSION}

The purpose of this study was illuminating the relationship between method of instruction and EFL learner's reading comprehension. As the results indicated, it was proved that there is a relationship between method of instruction and EFL learner's reading comprehension, given that the obtained results by class 2 was better than that of class 1 . This was due to the fact that the method of instruction for reading comprehension in class 2 caused less stress among the learners than that which was applied in class 1 . Therefore, more research should be conducted on methods of instruction and its effect on student's learning in different contexts in order to explore the efficiency and ways of expanding of such methods. The immediate benefit of this study can obviously be for teachers and instructors in order to go through the texts in a manner which can reduce the stress of the learners and lead to more productivity in this specific language skill. The findings may also provide curriculum developers and material designers with more information about the merits/demerits of teaching strategies in order to mention them in the teachers guide's books beside the course books.

\section{ACKNOWLEDGMENT}

We would like to show our gratitude to Dr. Ahmad Alibabaee for his comments on an earlier version of the manuscript, although any errors are our own and should not tarnish the reputations of this esteemed person.

\section{REFERENCES}

French, J. R. P., Cobb, S., Caplan, R. D., Van Harrison, R. and Pinneau, S. R. (1976). Job Demands and Worker Health. A symposium presented at the $84^{\text {th }}$ Annual Conference of the American Psychological Association.

Frey, N. (1980). Improving the Performance of Poor Readers through Autogenic Relaxation Training. The Reading Teacher, 928-932.

Hughes, H., K. Jackson, K. E. Du Bois, and R. Erwin. (1979) Treatment of Handwriting Problems Utilizing EMG Biofeedback Training. Perceptual and Motor Skills, 48, 603-606.

Lazarus, Richard, S. (1966). Psychological Stress and The Coping Process. New York: McGraw-Hill.

Limbos, M. M. \&Geva, E. (2001). Accuracy of teacher assessments of second language students at risk for reading disability. Journal of learning disabilities, 34 (2). Retrieved from http://Action research project for an MAECDT degree.htm.

Saito, Y., Thomas, G. J., \&Horwitz, E. K., (1999). Foreign Language Reading Anxiety. The Modern Language Journal, 83(2), 202-218. Retrieved from http://ESLEFL Reading Comprehension Tests and Anxiety.htm.

Sanz, C., (1999, October 8-10). The relationship between reading, anxiety, and reading comprehension. Paper presented at the 1999 Conference on L1 \& L2 Acquisition of Spanish and Portuguese \& Third Hispanic Linguistics Symposium. Abstract retrieved January 17, 2015, from http://data.georgetown.edu/departments/spanport/conferences/abstract.cfm?ID $=15$

Zhang, L. J. (2000). Uncovering Chinese ESL students' reading anxiety in a study abroad context. Asian Pacific Journal of Language in Education, 3 (2), 31- 52. Retrieved from http://Educationleadership.files.wordpress. com/2007/02/nelliedeutschmaedctarp.pdf. 